\title{
Palladium Nanoparticles Supported on Graphene Oxide as Catalysts for the Synthesis of Diarylketones
}

\author{
Anna M. Trzeciak ${ }^{1, *(\mathbb{D})}$, Przemyslaw Wojcik ${ }^{1}$, Radoslaw Lisiecki ${ }^{2}$, Yuriy Gerasymchuk ${ }^{2}$, \\ Wieslaw Strek ${ }^{2}$ and Janina Legendziewicz ${ }^{1}$ \\ 1 Faculty of Chemistry, Wrocław University, 14 F. Joliot-Curie 14 St., 50-383 Wrocław, Poland; \\ przemyslaw.wojcik@chem.uni.wroc.pl (P.W.); janina.legendziewicz@chem.uni.wroc.pl (J.L.) \\ 2 Institute of Low Temperature and Structure Research Polish Academy of Sciences, 2 Okolna St., \\ 50-422 Wroclaw, Poland; r.lisiecki@int.pan.wroc.pl (R.L.); j.gerasymchuk@int.pan.wroc.pl (Y.G.); \\ w.strek@int.pan.wroc.pl (W.S.) \\ * Correspondence: anna.trzeciak@chem.uni.wroc.pl
}

Received: 5 March 2019; Accepted: 28 March 2019; Published: 1 April 2019

\begin{abstract}
Three palladium catalysts supported on graphene oxide (GO) and on its composite with $\mathrm{TiO}_{2}\left(\mathrm{GO}-\mathrm{TiO}_{2}\right)$ were prepared and characterized. The presence of Pd NPs of different diameters $(4-89 \mathrm{~nm})$ and size distributions was evidenced by TEM measurements. GO-supported palladium efficiently catalysed the carbonylative coupling of iodobenzenes with aryl boronic acids forming relevant diarylketones at $1 \mathrm{~atm} \mathrm{CO}$. The highest activity and recyclability were obtained for $\mathrm{Pd} / \mathrm{GO}-\mathrm{TiO}_{2}$. The emission behaviour of $\mathrm{Pd} / \mathrm{GO}$ and $\mathrm{Pd} / \mathrm{GO}-\mathrm{TiO}_{2}$ catalysts indicated structural changes occurring during the catalytic reaction.
\end{abstract}

Keywords: palladium; graphene oxide; carbonylative coupling

\section{Introduction}

Carbon-based materials, such as graphene oxide (GO), reduced graphene oxide, multi-walled carbon nanotubes, and single-walled carbon nanotubes have already found many applications due to their physical and mechanical properties [1-4]. In particular, the electronic and optic properties of GO can be controlled by the ratio of the $\mathrm{sp}^{2}-$ to- $\mathrm{sp}^{3}$ hybridized carbons [5-8]. This is important for applications of GO in material chemistry and technology as transistors or sensors. Graphene oxide (GO) is also a promising material for the development of new immobilized metal catalysts, in particular containing palladium as an active phase [9-11]. The immobilization of the catalyst enables its efficient separation from organic products and use in subsequent catalytic runs. For these functions, the support should perfectly stabilize catalytically active palladium forms and prevent their leaching to the solution. Porous GO materials with a layered structure containing different functional groups able to form stable bonds with metals meet these expectations perfectly. In addition, a high surface-to-weight ratio, low mass density, and accessibility of differently modified centres make it possible to select GO for catalytic applications. The successful use of Pd/GO in the Suzuki-Miyaura reaction has been reported [12-25]. Not only high conversion but also good catalyst recyclability have been achieved. Only one example of the use of Pd/GO in the carbonylative Suzuki-Miyaura coupling leading to aryl ketones has so far been reported [26].

Because the interatomic distance of $\mathrm{Pd}(0.225 \mathrm{~nm})$ is close to the honeycomb spacing in graphene $(0.240 \mathrm{~nm})$, bonding between Pd and GO is possible [27]. The introduction of Pd to GO resulted in a decrease in the number of oxygen functional defects, while the number of $\mathrm{sp}^{2}$ carbon atoms and delocalized $\pi$-electrons increased. The change of the GO structure led to the modification of its optical properties including photoluminescence. Further changes of the optical properties could be expected 
as a result of the structural changes of the $\mathrm{Pd} / \mathrm{GO}$ composite under catalytic conditions, but this aspect has not been studied yet.

Our studies aimed at the synthesis of $\mathrm{Pd} / \mathrm{GO}$ and $\mathrm{Pd} / \mathrm{GO}-\mathrm{TiO}_{2}$ catalysts and testing their activity in the carbonylative Suzuki-Miyaura coupling. By the introduction of $\mathrm{TiO}_{2}$ to the GO support, we expected to increase the stability and recyclability of the palladium catalyst. Moreover, the presence of $\mathrm{TiO}_{2}$ increased the photocatalytic activity of GO [28,29]. The structural characteristics of the GO-immobilized palladium catalysts were obtained using different methods, including measurements of emission spectra. It was expected that the emission behaviour of the studied samples would be helpful in understanding the structural changes of the catalyst during the catalytic process.

\section{Results and Discussion}

Two catalysts supported on GO, Pd/GO-A and Pd/GO-B, were obtained by different procedures. $\mathrm{Pd} / \mathrm{GO}-\mathrm{A}$ was prepared from $\mathrm{PdCl}_{2}$ as the palladium source, in an acetonitrile solution at RT without any additional reducing agent. The TEM analysis evidenced the presence of $34-89 \mathrm{~nm}$ Pd NPs, partially agglomerated (Figure 1). Characteristic lines of the crystalline Pd NPs and GO were observed in the XRD picture (Figure 2). The second palladium catalyst, $\mathrm{Pd} / \mathrm{GO}-\mathrm{B}$, was obtained according to the literature method [24], using $\mathrm{Pd}(\mathrm{OAc})_{2}$ as the substrate and a sonication step as part of the synthetic procedure. The obtained composite, Pd/GO-B, contained Pd NPs of $c a$. 8-9 nm in diameter with a relatively narrow size distribution (Figure 3). The palladium content in $\mathrm{Pd} / \mathrm{GO}-\mathrm{B}$ was higher than in Pd/GO-A according to the ICP analysis. On the other hand, an EDX analysis showed lower Pd content values on the surface of Pd/GO-B than on the surface of Pd/GO-A.
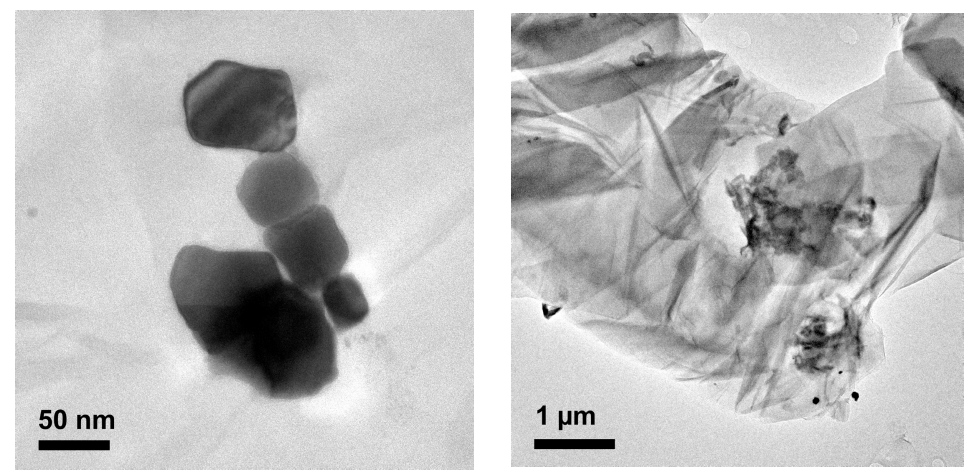

Figure 1. TEM pictures of Pd/GO-A.

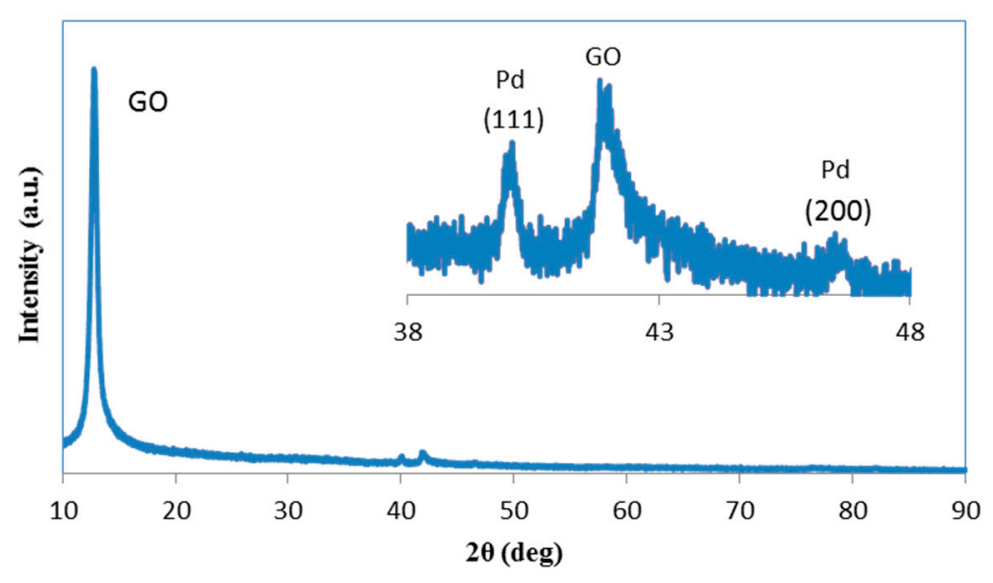

Figure 2. XRD of Pd/GO-A. 


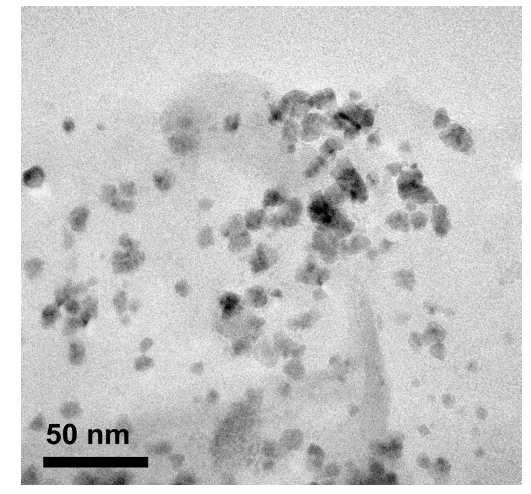

(a)

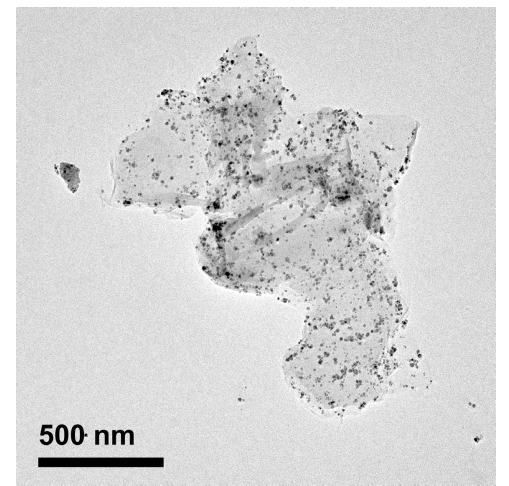

(b)

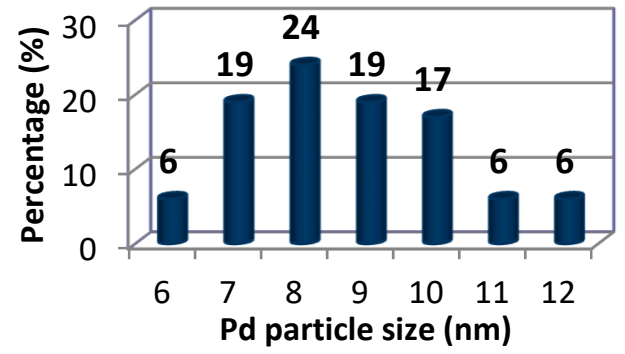

(c)

Figure 3. TEM pictures (a,b) and Pd NPs size distribution (c) for Pd/GO-B.

The synthesis of Pd/GO-TiO 2 was performed according to the method used for Pd/GO-A. The presence of $\mathrm{TiO}_{2}$ in the support resulted in formation of small Pd NPs, uniformly distributed on the surface, as shown by the TEM pictures. However, the SEM/EDX analysis indicated low palladium amounts on the surface (0.01-0.06 atom\%). Moreover, the XRD measurement presented only lines originating from $\mathrm{GO}-\mathrm{TiO}_{2}$. The palladium lines were not visible, probably because of the small diameter of Pd NPs. It can be assumed that palladium in $\mathrm{Pd} / \mathrm{GO}-\mathrm{TiO}_{2}$ was localized mostly inside the support material, but not on its surface.

\subsection{Catalytic Activity of $P d / G O$}

The activity of $\mathrm{Pd} / \mathrm{GO}$ and $\mathrm{Pd} / \mathrm{GO}-\mathrm{TiO}_{2}$ catalysts was investigated in the carbonylative Suzuki-Miyaura cross-coupling of 4-iodoanisole with phenylboronic acid at $1 \mathrm{~atm}$ of $\mathrm{CO}$ (Figure 4, Table 1).

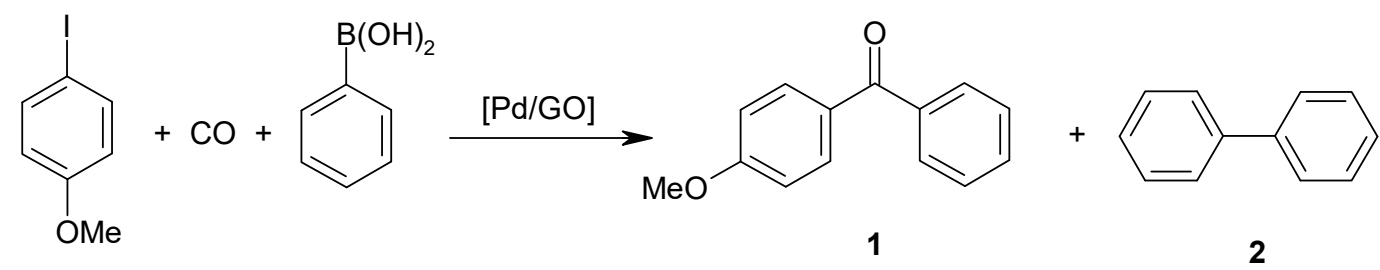

Figure 4. The carbonylative Suzuki-Miyaura reaction. 
Table 1. The carbonylative Suzuki-Miyaura reaction with GO-supported palladium ${ }^{\text {a }}$.

\begin{tabular}{|c|c|c|c|c|c|}
\hline Entry & Catalyst & $\begin{array}{c}\text { Conversion } \\
(\%)\end{array}$ & $\begin{array}{c}\text { Yield } 1 \\
(\%)\end{array}$ & $\begin{array}{c}\text { Yield } 2 \\
(\%)\end{array}$ & $\begin{array}{c}\text { Selectivity to } 1 \\
(\%)\end{array}$ \\
\hline 1 & $\mathrm{Pd} / \mathrm{GO}-\mathrm{A}$ & 78 & 70 & 7 & 91 \\
\hline 2 & Pd/GO-B & 82 & 74 & 7 & 90 \\
\hline 3 & $\mathrm{Pd} / \mathrm{GO}-\mathrm{TiO}_{2}$ & 95 & 89 & 6 & 94 \\
\hline 4 & $\mathrm{Pd} / \mathrm{C}(10 \%)$ & 88 & 82 & 6 & 93 \\
\hline
\end{tabular}

Reaction conditions: 4-iodoanisole (1 mmol); $\mathrm{PhB}(\mathrm{OH})_{2}(1.2 \mathrm{mmol}) ; 0.2 \mathrm{~mol} \%$ [Pd], $3 \mathrm{mmol} \mathrm{K}{ }_{2} \mathrm{CO}_{3}, 1$ atm CO, $5 \mathrm{~mL}$ anisole, $4 \mathrm{~h}, 100^{\circ} \mathrm{C}$. ${ }^{\mathrm{a}}$ Determined by GC using dodecane as the internal standard.

Under the applied conditions, all the catalysts studied showed a high activity and good selectivity to the desired ketone. The Pd/GO-A with the lowest palladium content $(0.26 \mathrm{wt} \%)$ and agglomerated $\mathrm{Pd}$ NPs presented the lowest catalytic activity, while the Pd/GO-B containing smaller and dispersed $\mathrm{Pd}$ NPs gave a slightly higher conversion. Among these three catalysts, $\mathrm{Pd} / \mathrm{GO}-\mathrm{TiO}_{2}$ turns out to present the highest catalytic activity with a conversion $95 \%$ and a selectivity to ketone of $94 \%$. These results were also better than those obtained using a commercial $\mathrm{Pd} / \mathrm{C}$ catalyst ( $88 \%$ conversion).

\subsection{Optimization of the Reaction Conditions for $\mathrm{Pd} / \mathrm{GO}-\mathrm{TiO}_{2}$}

The influence of the reaction parameters, such the amount of the base, temperature and reaction time, was studied for the $\mathrm{Pd} / \mathrm{GO}-\mathrm{TiO}_{2}$ catalyst (Table 2).

Table 2. Optimization of the carbonylative Suzuki-Miyaura reaction using $\mathrm{Pd} / \mathrm{GO}-\mathrm{TiO}_{2}{ }^{\mathrm{a}}$.

\begin{tabular}{|c|c|c|c|c|c|c|c|c|}
\hline Entry & $\begin{array}{l}\text { Catalyst Loading } \\
\text { (mol\%) }\end{array}$ & $\begin{array}{l}\mathrm{K}_{2} \mathrm{CO}_{3} \\
(\mathrm{mmol})\end{array}$ & Solvent & $\begin{array}{l}\text { Temp. } \\
\left({ }^{\circ} \mathrm{C}\right)\end{array}$ & $\begin{array}{l}\text { Time } \\
\text { (h) }\end{array}$ & $\begin{array}{l}\text { Conversion } \\
(\%)\end{array}$ & $\begin{array}{l}\text { Yield } 1 \\
(\%)\end{array}$ & $\begin{array}{c}\text { Yield } 2 \\
(\%)\end{array}$ \\
\hline 1 & 0.23 & 3 & Anisole & 100 & 5 & 96 & 91 & 5 \\
\hline 2 & 0.2 & 3 & Anisole & 100 & 4 & 95 & 89 & 6 \\
\hline 3 & 0.2 & 2 & Anisole & 100 & 4 & 92 & 85 & 7 \\
\hline 4 & 0.2 & 1 & Anisole & 100 & 4 & 77 & 72 & 5 \\
\hline 5 & 0.2 & 3 & Anisole & 100 & 3 & 81 & 79 & 2 \\
\hline 6 & 0.2 & 3 & Dioxane & 100 & 3 & 60 & 55 & 5 \\
\hline 7 & 0.2 & 3 & Anisole & 80 & 3 & 51 & 51 & 0 \\
\hline 8 & 0.2 & 3 & Water & 80 & 3 & 26 & 5 & 21 \\
\hline
\end{tabular}

Reaction conditions: 4-iodoanisole $(1 \mathrm{mmol}) ; \mathrm{PhB}(\mathrm{OH})_{2}(1.2 \mathrm{mmol}) ; 1 \mathrm{~atm} \mathrm{CO}, 5 \mathrm{~mL}$ solvent, $4 \mathrm{~h}, 100{ }^{\circ} \mathrm{C}$.

${ }^{a}$ Determined by GC using dodecane as the internal standard.

A reaction time of $4 \mathrm{~h}$ was sufficient for the maximum $95 \%$ conversion, while $81 \%$ was achieved after $3 \mathrm{~h}$. Lowering the amount of $\mathrm{K}_{2} \mathrm{CO}_{3}$ from 3 to $1 \mathrm{mmol}$ resulted in a conversion decrease to $77 \%$ due to a less efficient transmetallation process. Changing the solvent from anisole to dioxane caused a decrease in conversion, while water promoted the formation of the Suzuki-Miyaura product.

The influence of the daylight was also investigated considering possible photoactivation with $\mathrm{TiO}_{2}$. However the results obtained with or without exposure to light were practically the same.

\subsection{Substrate Screening in the Carbonylative Suzuki-Miyaura Coupling}

The optimized reaction conditions were next used in investigations of reactions with different aryl iodides and aryl boronic acids catalysed by the $\mathrm{Pd} / \mathrm{GO}-\mathrm{TiO}_{2}$ catalyst (Figure 5, Table 3).<smiles>[R]c1ccc(I)cc1</smiles><smiles>[R]c1ccc(C(=O)c2ccc([R2])cc2)cc1</smiles>

Figure 5. The carbonylative Suzuki-Miyaura reaction. 
Table 3. Substrate screening using $\mathrm{Pd} / \mathrm{GO}-\mathrm{TiO}_{2}$ a

\begin{tabular}{|c|c|c|c|c|c|c|}
\hline Entry & Iodoarene & Arylboronic Acid & $\begin{array}{c}\text { Conversion } \\
(\%)\end{array}$ & $\begin{array}{l}\text { Yield 1A } \\
(\%)\end{array}$ & $\begin{array}{l}\text { Yield 2A } \\
(\%)\end{array}$ & $\begin{array}{c}\text { Selectivity to } 1 \mathrm{~A} \\
(\%)\end{array}$ \\
\hline 1 & & & 95 & $66\left(57^{b}\right)$ & 27 & 72 \\
\hline 2 & & & 56 & 52 & 4 & 93 \\
\hline 3 & & & 73 & $55\left(42^{b}\right)$ & 18 & 75 \\
\hline 4 & & & 95 & $89\left(80^{b}\right)$ & 6 & 94 \\
\hline 5 & & & 87 & $62\left(50^{b}\right)$ & 25 & 71 \\
\hline 6 & & & 97 & $85\left(77^{b}\right)$ & 12 & 88 \\
\hline 7 & & & 97 & $69\left(58^{b}\right)$ & 28 & 71 \\
\hline
\end{tabular}

Reaction conditions: iodoarene (1 mmol), arylboronic acid (1.2 mmol), Pd/GO- $\mathrm{TiO}_{2} 0.2 \mathrm{~mol} \%, 3 \mathrm{mmol} \mathrm{K}{ }_{2} \mathrm{CO}_{3}$, $1 \mathrm{~atm}$ CO, $5 \mathrm{~mL}$ anisole, $4 \mathrm{~h}, 100^{\circ} \mathrm{C}$. a Determined by GC using dodecane as the internal standard. ${ }^{\mathrm{b}}$ Yield of the isolated product.

The Pd/GO-TiO 2 catalyst also provided very good results in both conversion and selectivities by using different aryl iodides and aryl boronic acids under the optimized reaction conditions. The best conversions were achieved using 4-methyl-1-naphthaleneboronic acid, phenylboronic acid, 2-iodothiophene, and 1-iodonaphthalene (entries 1, 4, 6, 7). The highest selectivity to ketone was obtained by using 3-vinyl-phenylboronic acid and phenylboronic acid (entries 2, 4).

All in all, conversions up to $97 \%$ as well as selectivity to ketone up to $94 \%$ could be achieved using a $\mathrm{Pd} / \mathrm{GO}-\mathrm{TiO}_{2}$ catalyst.

\subsection{Recycling of $\mathrm{Pd} / \mathrm{GO}-\mathrm{B}$ and $\mathrm{Pd} / \mathrm{GO}-\mathrm{TiO}_{2}$ Catalysts}

Attempts at catalyst recycling were performed for Pd/GO-B and Pd/GO-TiO 2 (Table 4). The first carbonylative Suzuki-Miyaura reaction was carried out under the given reaction conditions. Next, the organic products were extracted with hexane, and a new portion of the reactants was added to the catalyst remaining in the anisole solution. The activity of the Pd/GO-B catalyst decreased rather fast in subsequent runs, and conversion dropped from $87 \%$ in the first reaction to $48 \%$ in the third one. 
In contrast, $\mathrm{Pd} / \mathrm{GO}-\mathrm{TiO}_{2}$ was more stable, and a conversion decrease from $97 \%$ to $80 \%$ was noted after four runs. During recycling, some decrease of the selectivity to ketone was observed as a result of 2-methylbiphenyl, the product formed by the normal Suzuki-Miyaura coupling.

Table 4. Recycling of $\mathrm{Pd} / \mathrm{GO}-\mathrm{TiO}_{2}$ in the carbonylative Suzuki-Miyaura cross-coupling reaction ${ }^{\mathrm{a}}$.

\begin{tabular}{cccccc}
\hline Entry & $\begin{array}{c}\text { Recycling } \\
\text { Run }\end{array}$ & $\begin{array}{c}\text { Conversion } \\
\mathbf{( \% )}\end{array}$ & $\begin{array}{c}\text { Yield 1 } \\
\mathbf{( \% )}\end{array}$ & $\begin{array}{c}\text { Yield 2 } \\
\mathbf{( \% )}\end{array}$ & $\begin{array}{c}\text { Selectivity to 1 } \\
\mathbf{( \% )}\end{array}$ \\
\hline 1 & 0 & 97 & 94 & 3 & 97 \\
2 & 1 & 98 & 82 & 16 & 84 \\
3 & 2 & 84 & 66 & 18 & 78 \\
4 & 3 & 80 & 63 & 17 & 79 \\
\hline
\end{tabular}

Reaction conditions: 4-iodoanisole (1 mmol); $\mathrm{PhB}(\mathrm{OH})_{2}(1.2 \mathrm{mmol}) ; 0.17 \mathrm{~mol} \%$ [Pd], $3 \mathrm{mmol} \mathrm{K}{ }_{2} \mathrm{CO}_{3}, 1 \mathrm{~atm} \mathrm{CO}$, $5 \mathrm{~mL}$ anisole, $4 \mathrm{~h}, 100^{\circ} \mathrm{C}$. ${ }^{a}$ Determined by GC using dodecane as the internal standard.

The observed decrease of catalytic activity during recycling can be explained, at least partially, by the loss of some palladium during extraction of products. It should also be stressed that the recycling experiments were performed using only $0.17 \%$ of $\mathrm{Pd} / \mathrm{GO}-\mathrm{TiO}_{2}$.

In order to determine whether the Pd nanoparticles are responsible for the catalytic activity, the mercury test was performed [30]. According to the literature, the addition of $\mathrm{Hg}(0)$ to the reaction mixture should result in the formation of inactive $\mathrm{Pd} / \mathrm{Hg}$ amalgam and retarding of the catalytic process. When 500 -fold excess of $\mathrm{Hg}(0)$ was added to the catalytic system together with substrates, no conversion of iodobenzene was noted. Therefore, it is reasonable to conclude that in this reaction palladium nanoparticles are involved in the catalytic process taking place on their surface. On the other hand, SEM/EDX analyses shown small decrease of Pd content on the surface of $\mathrm{Pd} / \mathrm{GO}-\mathrm{TiO}_{2}$ from $0.2-0.25$ atom \% before catalytic reaction to $0.2-0.22$ atom $\%$ after the reaction, indicating on possible palladium leaching. In conclusion, we propose contribution of both, palladium nanoparticles and underligated palladium species, in the catalytic process.

\subsection{Luminescent Studies of Pd/GO Catalysts}

After the characterization of the catalytic properties of palladium supported on GO materials, spectroscopic studies were undertaken to get deeper knowledge about structural changes occurring during the reaction (see Figure 6). We used excitation lines $\left(\lambda_{\mathrm{ex}}=300,445,488,800 \mathrm{~nm}\right.$ ) similar to those in the excitation of graphene ceramics. In the case of GO emission, the observed shapes of emission bands were similar regardless of the excitation lines used. However, their intensities were different. For example, the intensity of the emission for $\lambda_{\mathrm{ex}}=488 \mathrm{~nm}$ was significantly lower for $\mathrm{GO}-\mathrm{TiO}_{2}$ than for GO, due to the recombination decrease in the electron-hole process after C-Ti bond formation.

The addition of $\mathrm{Pd}$ to $\mathrm{GO}$ and $\mathrm{GO}-\mathrm{TiO}_{2}$ materials caused a remarkable increase in emission intensity for $\lambda_{\mathrm{ex}}=800 \mathrm{~nm}$ and $445 \mathrm{~nm}$. The same effect was also noted using $\lambda_{\mathrm{ex}}=488 \mathrm{~nm}$ for $\mathrm{GO}^{-} \mathrm{TiO}_{2}$, while grafting of Pd on GO did not change this emission intensity. The enhanced blue emission after the introduction of Pd indicated the reduction of GO and increase in the number of $\pi$-electrons [27].

Further changes of emission spectra were observed in samples recovered after the catalytic process. A comparison of emission spectra of $\mathrm{Pd} / \mathrm{GO}-\mathrm{TiO}_{2}$ before and after the catalytic reaction $\left(\mathrm{Pd} / \mathrm{GO}-\mathrm{TiO}_{2}-\mathrm{R}\right)$ showed a significant decrease in emission intensity at $\lambda_{\mathrm{ex}}=445$ and $488 \mathrm{~nm}$. For $800 \mathrm{~nm}$, however, the line became broader, and its intensity decreased only slightly. Significant changes were detected in the shapes and intensities of the lines in the spectra of Pd/GO and Pd/GO-R. In all three experiments, the emission lines measured for the post-reaction samples (Pd/GO-R) presented the highest intensity. It is worth noting that the reactants used in the catalytic process did not emit in the studied spectra range. Therefore, the observed changes can be interpreted in relation to the structural changes of Pd/GO catalysts. 


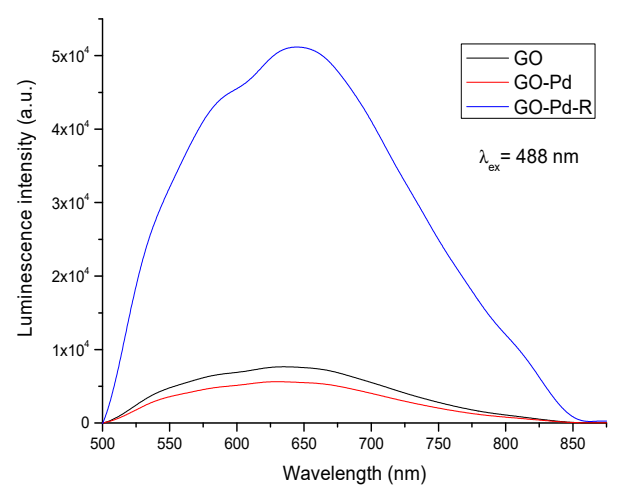

(a)

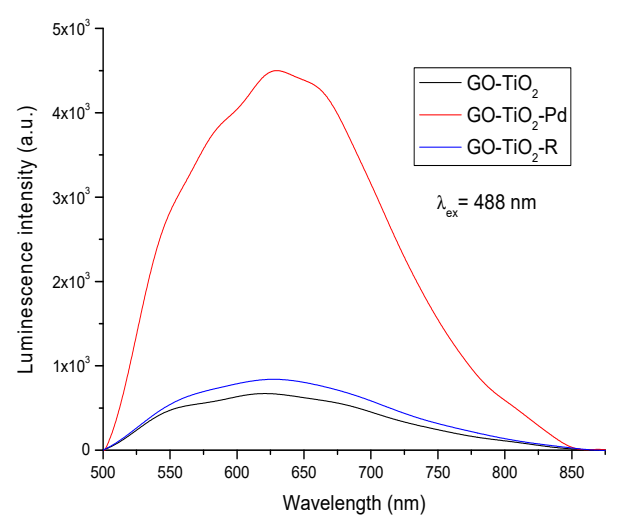

(c)

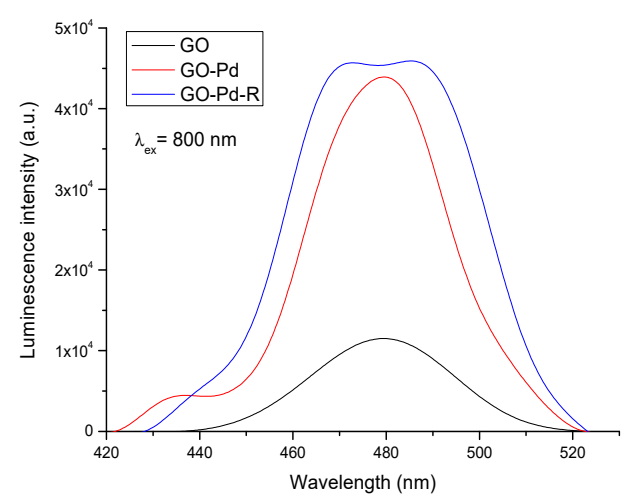

(b)

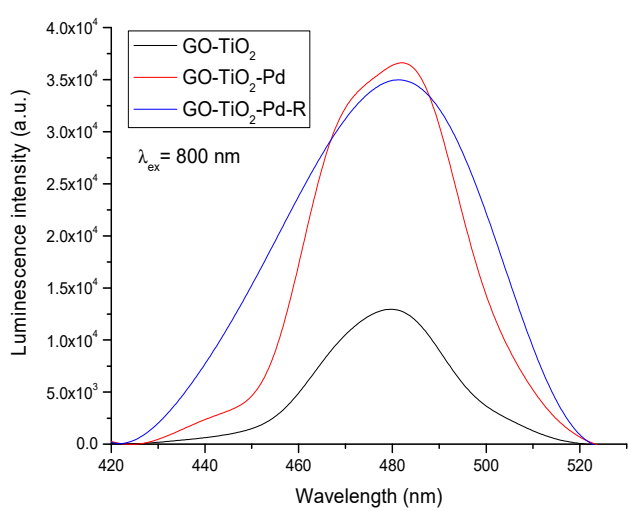

(d)

Figure 6. Emission spectra of $\mathrm{Pd} / \mathrm{GO}(\mathbf{a}, \mathbf{b})$ and $\mathrm{Pd} / \mathrm{GO}-\mathrm{TiO}_{2}(\mathbf{c}, \mathbf{d})$ at different excitation lines.

The analysis of emission spectra indicated different behaviours of $\mathrm{Pd} / \mathrm{GO}-\mathrm{TiO}_{2}$ and $\mathrm{Pd} / \mathrm{GO}$ under the catalytic conditions (see Supplementary Materials). The observed decrease in line intensities observed for $\mathrm{Pd} / \mathrm{GO}-\mathrm{TiO}_{2}$ can be explained by a decrease in the number of $\mathrm{sp}^{2}$ clusters in the GO composite. Although the mechanism of the emission process is not fully explained, the observed effects suggested the participation of the $\mathrm{GO}-\mathrm{TiO}_{2}$ support in the catalytic reaction. Such synergistic interaction of palladium and the support can increase the catalytic activity and stability of the $\mathrm{Pd} / \mathrm{GO}-\mathrm{TiO}_{2}$ catalyst.

\section{Experimental}

\subsection{Synthesis of $P d / G O-A$}

Graphene oxide (GO, $0.2 \mathrm{~g}$ ) [31] was placed in a $50 \mathrm{~mL}$ flask, and $10 \mathrm{~mL}$ of dry acetonitrile was added. In a second $50 \mathrm{~mL}$ flask, the $\mathrm{PdCl}_{2}(\mathrm{MeCN})_{2}$ complex $(0.1 \mathrm{~g})$ was solved in $20 \mathrm{~mL}$ of dry acetonitrile. The solution of the palladium complex was slowly added to the stirred solution of GO under a nitrogen atmosphere. The reaction mixture was stirred for 1 day at RT. Next, the solution was filtered, and the obtained solid was washed with diethyl ether $(20 \mathrm{~mL})$ and acetonitrile $(15 \mathrm{~mL})$ and dried. Yield: $166 \mathrm{mg}$. The palladium content (according to ICP analysis) was 0.26 weight \%. The Pd/GO-A was also analysed by TEM, SEM, and XRD (Figures 1, 2 and 7). 


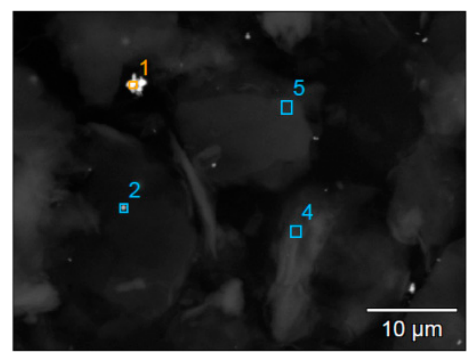

Figure 7. SEM pictures of Pd/GO-A. The content of $\mathrm{Pd}$ ranged from 0.28 to 10.20 atom $\%$ and the $\mathrm{Cl}$ content was $0.18-0.36$ atom $\%$.

\subsection{Synthesis of $P d / G O-B$}

Graphene oxide $(\mathrm{GO}, 0.2 \mathrm{~g}))$ [31] and $\mathrm{Pd}(\mathrm{OAc})_{2}(0.1 \mathrm{~g})$ were dissolved in $40 \mathrm{~mL}$ of dry toluene under a nitrogen atmosphere. The reaction mixture was sonicated for $50 \mathrm{~min}$, heated under reflux for $1 \mathrm{~h}$, and then stirred for 1 day at RT. Next, the solution was filtered, and the obtained solid was washed with diethyl ether $(15 \mathrm{~mL})$, ethanol $(15 \mathrm{~mL})$. and acetone $(10 \mathrm{~mL})$ and dried. Yield: $152 \mathrm{mg}$. The palladium content (according to ICP analysis) was 4.95 weight $\%$. The Pd/GO-B was analysed by TEM, SEM, and XRD (Figures 3, 8 and 9).

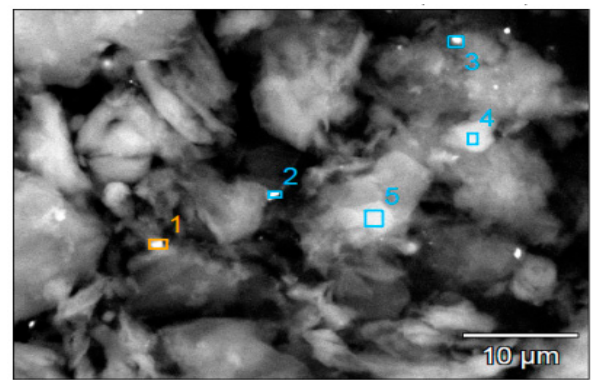

Figure 8. SEM picture of Pd/GO-B. The content of Pd ranged from 0.23 to 2.99 atom $\%$ and the $\mathrm{Cl}$ content was $0.21-0.28$ atom $\%$.

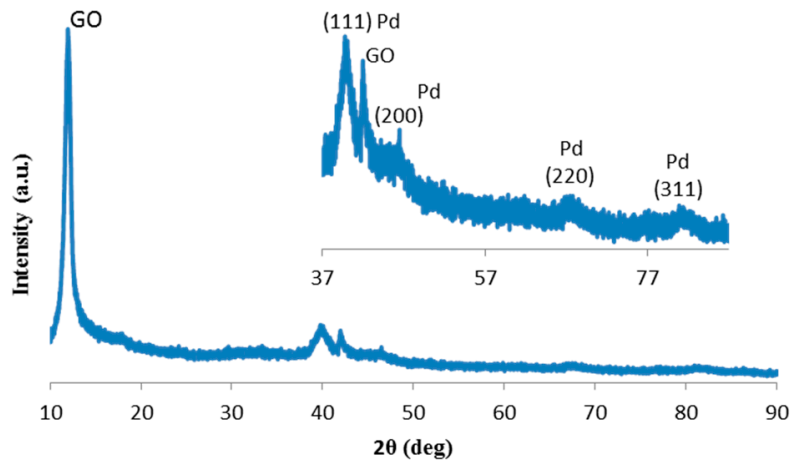

Figure 9. $\mathrm{XRD}$ of $\mathrm{Pd} / \mathrm{GO}-\mathrm{B}$.

\subsection{Synthesis of $\mathrm{Pd} / \mathrm{GO}-\mathrm{TiO}_{2}$}

Titanium-dioxide-modified graphene oxide $\left(\mathrm{GO}-\mathrm{TiO}_{2}, 0.346 \mathrm{~g}\right)$ [28] was placed in a $50 \mathrm{~mL}$ flask, and $10 \mathrm{~mL}$ of dry acetonitrile was added. In a second $50 \mathrm{~mL}$ flask, the $\mathrm{PdCl}_{2}\left(\mathrm{MeCN}_{2}\right.$ complex $(0.173 \mathrm{~g})$ was dissolved in $20 \mathrm{~mL}$ of dry acetonitrile. The solution of the palladium complex was slowly added to the stirred solution of $\mathrm{GO}-\mathrm{TiO}_{2}$ under nitrogen atmosphere. The reaction mixture was stirred for 1 day at RT. Next, the solution was filtered, and the obtained solid was washed with diethyl ether $(20 \mathrm{~mL})$ and acetonitrile $(15 \mathrm{~mL})$ and dried. Yield: $322 \mathrm{mg}$. The palladium content (according to ICP analysis) was 1.21 weight $\%$. The Pd/GO-TiO ${ }_{2}$ was analysed by TEM, SEMs and XRD (Figures 10 and 11). 


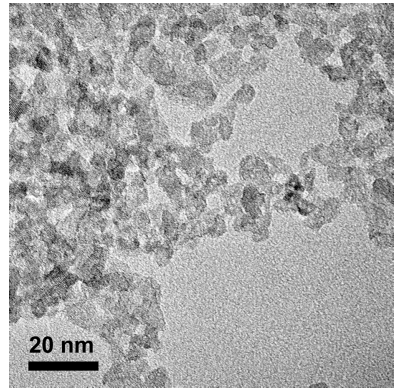

(a)

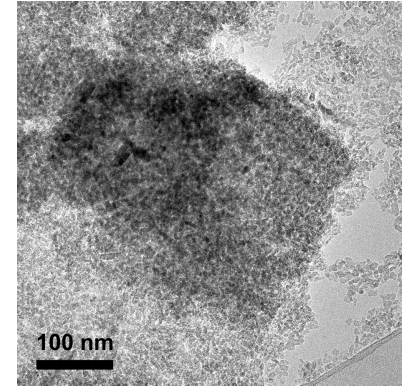

(b)

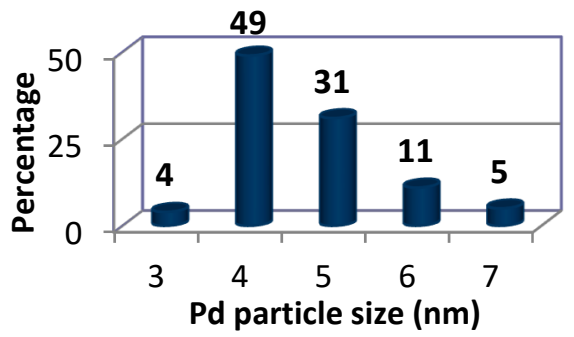

(c)

Figure 10. TEM pictures (a,b) and Pd NPs size distribution (c) for Pd/GO- $\mathrm{TiO}_{2}$.

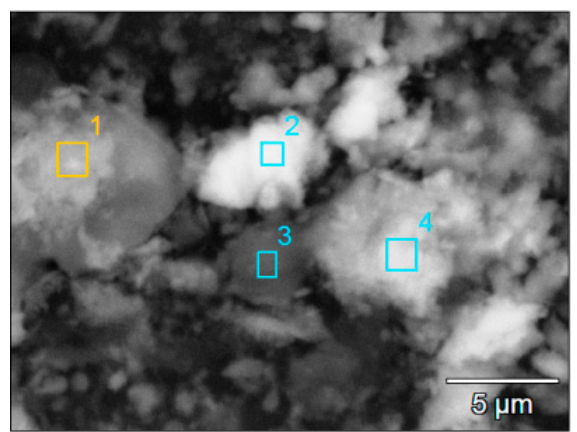

Figure 11. SEM picture of $\mathrm{Pd} / \mathrm{GO}-\mathrm{TiO}_{2}$. The content of $\mathrm{Pd}$ ranged from 0.01 to 0.06 atom $\%$ and $\mathrm{The} \mathrm{Cl}$ content was $0.52-1.87$ atom $\%$.

\subsection{Electron Absorption and Emission Spectra}

Room temperature electron absorption spectra were measured in the $200-1500 \mathrm{~nm}$ spectral range using a Cary-Varian 5E UV-VIS-near-IR spectrophotometer (Palo Alto, CA, USA). In the case of a weak signal of the spectrum, the spectrophotometer was switched to measurements in the reflectance mode.

Emission spectra were achieved using an excitation source consisting of a femtosecond laser (Coherent Model "Libra") coupled to an optical parametric amplifier (Light Conversion Model "OPerA"). The system delivers $100 \mathrm{fs}$ pulses at a repetition rate regulated up to $1 \mathrm{kHz}$ at a wavelength tuned between $230-2800 \mathrm{~nm}$. The excitation light was focused on samples using lens with a focal length of $15 \mathrm{~cm}$. The sample luminescence was observed in the direction perpendicular to the excitation beam. Appropriate long-pass filters were used to eliminate unwanted radiation. Emission spectra and luminescence decay curves were recorded with a grating spectrograph (Princeton Instr. Model Acton 2500i, Princeton, NJ, USA) coupled to a streak camera (Hamamatsu Model C5680, Tokyo, Japan), operating in the $200-1100 \mathrm{~nm}$ spectral region with a temporal resolution of $20 \mathrm{ps.} \mathrm{A} \mathrm{number} \mathrm{of}$ excitation laser sources were used, from the visible (VIS) up to the near-infrared (NIR) regime:

GC-FID and GC/MS measurements of organic products were performed using an HP5890 (Hewlett Packard, Palo Alto, CA, USA) instrument with a 5971A mass detector. Organic products were separated by flash chromatography (CombiFlash Rf 200, Changzhou, China) on silica gel.

ICP measurements of the palladium content were performed using an ARL 3410 model spectrometer. TEM measurements were carried out using a FEI Tecnai $G^{2} 20$ X-TWIN electron microscope operating at $200 \mathrm{kV}$ (Waltham, MA, USA).

\section{Conclusions}

The nanosize palladium catalysts, supported on $\mathrm{GO}$ and $\mathrm{GO}-\mathrm{TiO}_{2}$ were prepared from $\mathrm{PdCl}_{2}(\mathrm{MeCN})_{2}$ and $\mathrm{Pd}(\mathrm{OAc})_{2}$. An effect of the palladium precursor and the synthetic method on the structure of the catalyst was confirmed by physicochemical methods. The introduction of $\mathrm{Pd}$ to the GO matrix resulted in an increase in photoemission due to an increase in the number of $\mathrm{sp}^{2}$ 
centres. The GO-supported palladium exhibited high activity and selectivity in the carbonylative Suzuki-Miyaura coupling producing the relevant diarylketones at $1 \mathrm{~atm} \mathrm{CO}$ and a low amount of the catalyst $(0.2 \mathrm{~mol} \%)$. The best productivity, over $95 \%$ of the ketone, was noted for $\mathrm{Pd} / \mathrm{GO}-\mathrm{TiO}_{2}$, which was also successfully recycled in four subsequent runs. The emission spectra of the $\mathrm{Pd} / \mathrm{GO}-\mathrm{TiO}_{2}$ catalyst recovered after the catalytic process showed a decrease in the band intensity. This can be explained by the structural change and a recombination decrease in the electron-hole process. A better understanding of the emission process mechanism in Pd/GO composites requires further studies. However, our results showed that emission spectra can provide useful information about these catalytic systems.

Supplementary Materials: The following are available online at http:/ /www.mdpi.com/2073-4344/9/4/319/s1, Figure S1: Emission spectra of $\mathrm{Pd} / \mathrm{GO}$ and $\mathrm{Pd} / \mathrm{GO}-\mathrm{TiO}_{2}$ at $\lambda \mathrm{ex}=445 \mathrm{~nm}$.

Author Contributions: Conceptualization, A.M.T., W.S. and J.L.; Methodology, A.M.T., J.L.; Investigation, P.W., Y.G. and R.L.; Data curation, P.W. and R.L.; Writing—original draft preparation, A.M.T and J.L.; Writing—review and editing, A.M.T. and J.L.; Supervision, A.M.T.; Funding acquisition, A.M.T.

Acknowledgments: Financial support of National Science Fundation (NCN) with grant 2017/25/B/ST5/00394 is gratefully acknowledged (AT). Authors are grateful to Marek Hojniak (Faculty of Chemistry, University of Wroclaw) for GC and GC-MS analysis, to Wojciech Gil (Faculty of Chemistry, University of Wroclaw) for performing SEM and TEM measurements and to Sebastian Demmler (Leipzig University) for performance of catalytic studies.

Conflicts of Interest: The authors declare no conflict of interest.

\section{References}

1. Iijima, S. Helical microtubules of graphitic carbon. Nature 1991, 354, 56-58. [CrossRef]

2. Baughman, R.H.; Zakhidov, A.A.; de Heer, W.A. Carbon Nanotubes-The Route toward Applications. Science 2002, 297, 787-792. [CrossRef]

3. Castro, M.; Lu, J.; Bruzaud, S.; Kumar, B.; Feller, J.F. Carbon nanotubes/poly (e-caprolactone) composite vapour sensors. Carbon 2009, 47, 1930-1942. [CrossRef]

4. Loh, K.P.; Bao, Q.; Eda, G.; Chhowalla, M. Graphene oxide as a chemically tunable platform for optical applications. Nat. Chem. 2010, 2, 1015-1024. [CrossRef]

5. Liu, Z.; Wang, Y.; Zhang, X.; Xu, Y.; Chen, Y.; Tian, J. Nonlinear optical properties of graphene oxide in nanosecond and picosecond regimes. Appl. Phys. Lett. 2009, 94, 021902. [CrossRef]

6. Eda, G.; Mattevi, C.; Yamaguchi, H.; Kim, H.K.; Chhowalla, M. Insulator to Semimetal Transition in Graphene Oxide. Materials Science and Engineering, Rutgers University, Piscataway, New Jersey 08854. J. Phys. Chem. C 2009, 113, 15768-15771. [CrossRef]

7. Omidvar, A.; Rashidian Vaziri, M.R.; Jaleh, B. Enhancing the nonlinear optical properties of graphene oxide by repairing with palladium nanoparticles. Phys. E Low Diment. Syst. Nanostruct. 2018, 103, 239-245. [CrossRef]

8. Narayanam, P.K.; Sankaran, K. Optical behaviour of functional groups of graphene oxide. Mater. Res. Express 2016, 3, 105604. [CrossRef]

9. Rumi, L.; Scheuermann, G.M.; Mülhaupt, R.; Bannwarth, W. Palladium Nanoparticles on Graphite Oxide as Catalyst for Suzuki-Miyaura, Mizoroki-Heck, and Sonogashira Reactions. Helv. Chim. Acta 2011, 94, 966-976. [CrossRef]

10. Veisi, H.; Mirzaee, N. Ligand-free Mizoroki-Heck reaction using reusable modified graphene oxide-supported $\operatorname{Pd}(0)$ nanoparticles. Appl. Organomet. Chem. 2018, 32, e4067. [CrossRef]

11. Cheng, J.; Zhang, G.; Du, J.; Tang, L.; Xu, J.; Li, J. New role of graphene oxide as active hydrogen donor in the recyclable palladium nanoparticles catalyzed Ullmann reaction in environmental friendly ionic liquid/supercritical carbon dioxide system. J. Mater. Chem. 2011, 21, 3485-3494. [CrossRef]

12. Hemant Joshi, H.; Sharma, K.N.; Sharma, A.K.; Singh, A.K. Palladium-phosphorus/sulfur nanoparticles (NPs) decorated on graphene oxide: Synthesis using the same precursor for NPs and catalytic applications in Suzuki-Miyaura coupling. Nanoscale 2014, 6, 4588-4597. [CrossRef] [PubMed] 
13. Gao, S.; Shang, N.; Feng, C.; Wang, C.; Wang, Z. Graphene oxide-palladium modified Ag-AgBr: A visible-light-responsive photocatalyst for the Suzuki coupling reaction. RSC Adv. 2014, 4, 39242-39247. [CrossRef]

14. Singh, V.V.; Kumar, U.; Tripathi, S.N.; Singh, A.K. Shape dependent catalytic activity of nanoflowers and nanospheres of $\mathrm{Pd}_{4} \mathrm{~S}$ generated via one pot synthesis and grafted on graphene oxide for Suzuki coupling. Dalton Trans. 2014, 43, 12555-12563. [CrossRef]

15. Wang, X.; Chen, W.; Yan, L. Three-dimensional reduced graphene oxide architecture embedded palladium nanoparticles as highly active catalyst for the Suzuki-Miyaura coupling reaction. Mater. Chem. Phys. 2014, 148, 103-109. [CrossRef]

16. Hoseini, S.J.; Khozestan, H.G.; Fath, R.H. Covalent attachment of 3-(aminomethyl)pyridine to graphene oxide: A new stabilizer for the synthesis of a palladium thin film at the oil-water interface as an effective catalyst for the Suzuki-Miyaura reaction. RSC Adv. 2015, 5, 47701-47708. [CrossRef]

17. Scheuermann, G.M.; Rumi, L.; Steurer, P.; Bannwarth, W.; Rolf Mülhaupt, R. Palladium Nanoparticles on Graphite Oxide and Its Functionalized Graphene Derivatives as Highly Active Catalysts for the Suzuki-Miyaura Coupling Reaction. J. Am. Chem. Soc. 2009, 131, 8262-8270. [CrossRef] [PubMed]

18. Siamaki, A.R.; Khder, A.E.R.S.; Abdelsayed, V.; El-Shall, M.S.; Gupton, B.F. Microwave-assisted synthesis of palladium nanoparticles supported on graphene: A highly active and recyclable catalyst for carbon-carbon cross-coupling reactions. J. Catal. 2011, 279, 1-11. [CrossRef]

19. Moussa, S.; Siamaki, A.R.; Gupton, B.F.; El-Shall, M.S. Pd-Partially Reduced Graphene Oxide Catalysts (Pd/PRGO): Laser Synthesis of Pd Nanoparticles Supported on PRGO Nanosheets for Carbon-Carbon Cross Coupling Reactions. ACS Catal. 2012, 2, 145-154. [CrossRef]

20. Nishina, Y.; Miyata, J.; Kawai, R.; Gotoh, K. Recyclable Pd-graphene catalyst: Mechanistic insights into heterogeneous and homogeneous catalysis. RSC Adv. 2012, 2, 9380-9382. [CrossRef]

21. Sayedi, N.; Saidi, K.; Sheibani, H. Green Synthesis of Pd nanoparticles supported on magnetic graphene oxide by Origanum vilgae leaf plant extract: Catalytic activity in the reduction of organic dyes and Suzuki-Miyaura cross-coupling reaction. Catal. Lett. 2018, 148, 277-288. [CrossRef]

22. Surjyakanta Rana, S.; Maddila, S.; Yalagala, K.; Jonnalagadda, S.B. Organo functionalized graphene with Pd nanoparticles and its excellent catalytic activity for Suzuki coupling reaction. Appl. Catal. A Gen. 2015, 505, 539-547. [CrossRef]

23. Shang, N.; Gao, S.; Feng, C.; Zhang, H.; Wang, C.; Wang, Z.; Gao, S.; Feng, C.; Zhang, H.; Wang, C.; Wang, Z. Graphene oxide supported N-heterocyclic carbene-palladium as a novel catalyst for the Suzuki-Miyaura reaction. RSC Adv. 2013, 3, 21863-21868. [CrossRef]

24. Santra, S.; Hota, P.K.; Bhattacharyya, R.; Bera, P.; Ghosh, P.; Mandal, S.K. Palladium Nanoparticles on Graphite Oxide: A Recyclable Catalyst for the Synthesis of Biaryl Cores. ACS Catal. 2013, 3, 2776-2789. [CrossRef]

25. Gómez-Martínez, M.; Baeza, A.; Alonso, D.A. Graphene Oxide-Supported Oxime Palladacycles as Efficient Catalysts for the Suzuki-Miyaura Cross-Coupling Reaction of Aryl Bromides at Room Temperature under Aqueous Conditions. Catalysts 2017, 7, 94. [CrossRef]

26. Biying, A.O.; Vangala, V.R.; Chen, C.S.; Stubs, L.P.; Hosmane, N.S.; Yinghuai, Z. Cross-coupling reaction between arylboronic acids and carboranyl iodides catalyzed by graphene oxide (GO)-supported $\mathrm{Pd}(0)$ recyclable nanoparticles for the synthesis of carboranylaryl ketones. Dalton Trans. 2014, 43, 5014-5020. [CrossRef]

27. Rani, J.R.; Oh, J.; Park, J.; Lim, J.; Park, B.; Kim, K.; Kim, S.-J.; Jun, S.C. Controlling the luminescence emission from palladium grafted graphene oxide thin films via reduction. Nanoscale 2013, 5, 5620-5627. [CrossRef]

28. Min, Y.L.; Zhang, K.; Zhao, W.; Zheng, F.C.; Zhang, Y.G. Enhanced chemical interaction between $\mathrm{TiO}_{2}$ and graphene oxide for photocatalytic decolorization of methylene blue. Chem. Eng. J. 2012, 193-194, $203-210$. [CrossRef]

29. Huang, Q.; Tian, S.; Zeng, D.; Wang, X.; Song, W.; Li, Y.; Xiao, W.; Xie, C. Enhanced Photocatalytic Activity of Chemically Bonded $\mathrm{TiO}_{2}$ /Graphene Composites Based on the Effective Interfacial Charge Transfer through the C-Ti Bond. ACS Catal. 2013, 3, 1477-1485. [CrossRef] 
30. Phan, N.T.S.; van Der Sluys, M.; Jones, C.W. On the Nature of the Active Species in Palladium Catalyzed Mizoroki-Heck and Suzuki-Miyaura Couplings-Homogeneous or Heterogeneous Catalysis, A Critical Review. Adv. Synth. Catal. 2006, 348, 609-680. [CrossRef]

31. Szabó, T.; Tombácz, E.; Illés, E.; Dékány, I. Enhanced acidity and pH-dependent surface charge characterization of successively oxidized graphite oxides. Carbon 2006, 44, 537-545. [CrossRef]

(C) 2019 by the authors. Licensee MDPI, Basel, Switzerland. This article is an open access article distributed under the terms and conditions of the Creative Commons Attribution (CC BY) license (http:/ / creativecommons.org/licenses/by/4.0/). 